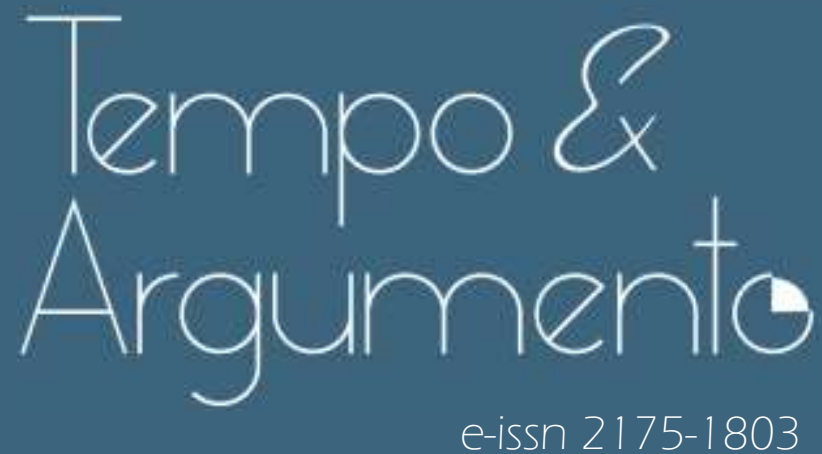

Memoria histórica e historia enseñada: construcciones simbólicas del futuro profesorado y su vínculo con la experiencia escolar

- Isidora Sáez-Rosenkranz

Doctora en Didáctica de las Ciencias Sociales y del Patrimonio y profesora de la Universidad de Barcelona.

Barcelona - ESPAÑA

researchgate.net/profile/Isidora_Saez-Rosenkranz

isidora.saez@ub.edu

(D) orcid.org/0000-0002-7453-609X

- Judit Sabido-Codina

Doctoranda del programa en Didáctica de las Ciencias, las Lenguas, las Artes y las

Humanidades de la Universidad de Barcelona.

Barcelona - ESPAÑA

researchgate.net/profile/Judit-Sabido-Codina

jsabido@ub.edu

(10) orcid.org/0000-0002-6323-4512

- Joaquín Prats Cuevas

Doctor en Historia Moderna y catedrático Emérito de la Universidad de Barcelona.

Barcelona - ESPAÑA

ub.edu/histodidactica/personal/

jprats@ub.edu

(D) orcid.org/0000-0002-8035-9368

Para citar este articulo (ABNT):

SÁEZ-ROSENKRANZ, Isidora; SABIDO-CODINA, Judit; PRATS CUEVAS, Joaquín.

Memoria histórica e historia enseñada: construcciones simbólicas del futuro profesorado y su vínculo con la experiencia escolar. Tempo e Argumento,

Florianópolis, v. 13, n. 33, e0 11 1, maio/ago. 2021

do http://dx.doi.org/10.5965/2175180313332021 e0111

Recebido: 26/02/2021

Aprovado: 23/05/2021 


\title{
Memoria histórica e historia enseñada: construcciones simbólicas del futuro profesorado y su vínculo con la experiencia escolar
}

\begin{abstract}
Resumen
Memoria histórica e historia reciente son conceptos cada vez más presentes en las aulas y más consolidados en la historiografía, siendo una problemática relevante en la construcción de las sociedades democráticas postransicionales. No obstante, en el aula, sigue siendo aún un campo que requiere investigar con más precisión algunos elementos que ayuden a entender mejor su incorporación en el proceso didáctico. El presente artículo analiza las construcciones simbólicas que tiene el futuro profesorado sobre la memoria y esboza un vínculo con su experiencia escolar, particularmente con las narrativas transmitidas en los libros de texto, en tanto principal recurso didáctico Se pretende contribuir al debate entre historia enseñada e historia investigada. La investigación, de tono hermenéutico, explora las conceptualizaciones y el papel que atribuyen a la memoria el futuro profesorado, relacionado con el papel que juegan los libros de texto a partir de la información recogida en un cuestionario construido ex profeso y las narrativas presentes en los libros de texto, que han construido una visión imprecisa y parcial de la memoria. De esta manera, evidenciamos la necesidad de repensar las relaciones entre historia reciente y memoria desde un punto de vista didáctico, tanto en los libros de texto como en la formación inicial del profesorado.
\end{abstract}

Palabras clave: memoria histórica; historia enseñada; libro de texto; conceptualizaciones; futuro profesorado.

\section{Historical memory and history taught: symbolic constructs of prospective teachers and their link to school experience}

\begin{abstract}
Historical memory and recent history are concepts increasingly more present in classrooms and more consolidated in historiography, being a relevant issue in the building of post-transitional democratic societies. However, in the classroom, it is still a field that requires more accurate research on some elements that help to better understand its incorporation in the didactic process. This article analyzes the symbolic constructs of prospective teachers regarding memory and outlines a link to their school experience, particularly to the narratives found in textbooks, as the main didactic resource. The aim is contributing to the debate between history taught and history inquired into. The research, which has taken a hermeneutic tone, addresses the conceptualizations and the role assigned to memory by prospective teachers, related to the role played by textbooks starting from information collected by using a questionnaire built on purpose and the narratives found in textbooks, which have conveyed an inaccurate and partial view of memory. Thus, we highlight the need to rethink the relationship between recent history and memory from a didactic viewpoint, both in textbooks and in early teachers training.
\end{abstract}

Keywords: historical memory; history taught; textbook; conceptualizations; prospective teachers. 


\section{Introducción}

La cuestión de la memoria histórica o democrática ${ }^{1}$ en sociedades postransicionales no es tema baladí, en general, y aún menos, desde el punto de vista educativo, puesto que está estrechamente relacionada con el ejercicio democrático (JELIN, 2013). En la escuela, y dentro de ella, en la enseñanza de Historia, la memoria otorga historicidad a los colectivos humanos, ofreciendo miradas comprensivas al pasado y al presente, que contribuyen a una integración de grupos sociales (RUBIO, 2007).

Sin embargo, estas consideraciones, al menos en España, no han estado seguidas de un adecuado y preciso tratamiento educativo desde las directrices institucionales (currículum), ni en los materiales o recursos educativos, especialmente en los libros de texto. Este vacío viene condicionado por las tardías políticas públicas de memoria en España (Ley No. 13/2007; Ley No. 10/2009; y Ley No. 11/2017), las que a su vez se han centrado en la recuperación y promoción de la memoria en espacios públicos y la generación de ciertas memorias, también en la esfera pública (BARREIRO, 2017). Así, las políticas de memoria en España, de carácter selectivo, están muy lejos de otras políticas que se han realizado en otros Estados europeos o latinoamericanos, con una experiencia más vasta y que ha involucrado sistemas judiciales, educativos y culturales.

De esta manera, la memoria se ha construido desde lugares públicos civiles, principalmente asociados a los procesos de Guerra Civil (1936-1939) y Franquismo (1939-1978) (JELIN, 2013), omitiendo otras memorias relacionadas

\footnotetext{
Existente en un debate, al menos en España, sobre la conceptualización de la memoria y también dentro de los propios estudios de memoria. Pero, como señala Jelin (2013), la terminología que la define está relacionada con las características de las distintas políticas de memoria. Sin embargo, nos decantamos aquí por el uso más genérico de memoria histórica, o simplemente memorias, por 2 razones. La primera, y sin intentar incidir en el debate teórico, adherimos a las posturas que consideran que la Historia recoge procesos sociales que incluyen diversos sujetos históricos y su papel en un margo general social más amplio. Bajo esta mirada, la contradicción evidenciada por Halbwachs (1995) entre historia y memoria y, por consiguiente, del propio concepto de memoria histórica, seria propia del momento de desarrollo de la ciencia histórica en la que escribió el autor. Por otra parte, el concepto de memoria histórica nos permite ligarla con la historia enseñada y, a partir de aquí, cuestionar los estereotipos de los que es objeto al estar institucionalizada en la escuela. En cualquier caso, en España se está extendiendo, cada vez más, el concepto de memoria democrática para obviar algunas confusiones producidas que han sido objeto de debate entre historiadores y políticos.
} 
con temporalidades y sujetos más amplios o temáticas diferentes al conflicto bélico o la represión totalitaria.

Los sistemas educativos, en tanto reflejo del mundo público (ARENDT, 1996), han replicado esta visión restringida de la memoria y, por tanto, su promoción ha quedado relegada, en la mayoría de casos, a la acción individual del profesorado (MARTíNEZ, 2014).

De la misma manera, el campo investigador tampoco ha incidido con suficiente énfasis en estas cuestiones. Las investigaciones sobre enseñanza de la memoria, al menos en España, son escasas, a pesar de que existe un corpus medianamente amplio sobre temas asociados como la educación en valores democráticos o educación para la paz. Incluso, la propia didáctica de la Historia, en investigaciones de los últimos diez años, ha puesto un mayor énfasis en la dimensión ciudadana (LÓPEZ-FACAL; VALLS, 2012; GÓMEZ; LÓPEZ; RODRíGUEZ, 2019) y se han acuñado conceptos didácticos como el tratamiento de los problemas socialmente relevantes, que incluyen el tratamiento didáctico del conflicto y la memoria, entre otros temas.

A pesar de este avance, desde el punto de vista de la investigación, el análisis de la memoria en los libros de texto es relativamente nuevo y está, todavía, en construcción. A pesar de la larga trayectoria que tienen estos materiales como campo de estudio (FUCHS; HENNE, 2018), y que como contenido educativo apareciese en España por primera vez en el año 1991, en el Diseño Curricular Base que acompañaba la nueva ley de educación (LOGSE)², son muy limitadas las investigaciones que abordan temáticas de memoria en los libros de texto. Menos frecuentes son los estudios que exploran la relación entre contenidos escolares y construcciones simbólicas del futuro profesorado, aun cuando es reconocida la importancia que tiene la educación formal en la construcción de narrativas, la cultura y los sistemas de pensamiento (BOURDIEU, 1983).

Según los resultados recientes del Proyecto Edumemorias (www.ub.edu/edumemorias), observamos un peso más relevante de la memoria a nivel de currículum y materiales educativos en los currículums y libros de texto asociados a la ley educativa del año 2014. 
En este contexto, la investigación que presentamos tiene como objetivos:

- Explorar las construcciones que tiene el profesorado en formación sobre la memoria; y

- Esbozar un vínculo con su experiencia escolar, particularmente con las narrativas transmitidas en los libros de texto.

Para ello, es necesario rastrear, por un lado, las características del conocimiento escolar desde la vertiente de los productores de contenidos educativos (currículum y libros de texto) y, por otro, considerar el papel que tiene el público -en este caso, el profesorado- a la hora de emplearlos y/o seleccionarlos (WILLIAMS, 1981). Ello permitiría comprender, y por tanto proyectar, el conocimiento y las conceptualizaciones del futuro profesorado respecto a estos temas, en tanto productor y reproductor de discursos. El estudio integra diversas dimensiones que se ubican en el punto de encuentro entre narrativa y experiencia que configuran la cultura (WILLIAMS, 2000), en este caso escolar.

En primer lugar, consideramos como punto de partida el papel que tienen los libros de texto -en tanto que constituyen el principal recurso educativo-, en las construcciones de narrativas. En segundo lugar, nos aproximamos a las características de la construcción del conocimiento escolar en tanto "historia pública". En tercero, recogemos la experiencia escolar como generadora de códigos simbólicos y, finalmente, nos adentramos en la mirada crítica a las narrativas en tanto reflejo integrado de los elementos anteriores. Por tanto, el estudio que proponemos no busca ser una investigación circunscrita propiamente al campo didáctico, ni tampoco aspira a ser una investigación estrictamente histórica o cultural, sino que apunta a establecer un diálogo entre ambas y aportar una visión reflexiva que las integre desde una mirada interpretativa a partir de datos empíricos.

Con este objeto, nos aproximamos a nuestra temática desde un locus hermenéutico ${ }^{3}$, puesto que consideramos que es la mirada que nos permite

Debido a la aproximación hermenéutica que nos interesa y con tal de priorizar las interpretaciones, se ha optado por reducir al mínimo indispensable las referencias a datos empíricos en el cuerpo del documento. Sin embargo, las evidencias que sustentan las afirmaciones se aportan como notas al pie de página. Cabe hacer notar que, al citar fragmentos de las respuestas dadas por el futuro profesorado, se identifican mediante el código asociado a cada cuestionario. 
Memoria histórica e historia enseñada: construcciones simbólicas del futuro profesorado y su vínculo con la experiencia escolar

Isidora Sáez-Rosenkranz, Judit Sabido-Codina, Joaquín Prats Cuevas

explorar las relaciones entre modelos teóricos y datos empíricos de las disciplinas con las que dialoga esta investigación: didáctica, memoria e historia. En consecuencia, podemos delinear una visión comprensiva y explicativa a las conceptualizaciones que tiene el futuro profesorado sobre la memoria.

Es importante señalar que las narrativas fueron recogidas a través de un cuestionario exploratorio breve ${ }^{4}$, aplicado intencionalmente a 252 estudiantes de magisterio de 2 universidades catalanas, una pública $(\mathrm{n}=188)$ y otra privada $(\mathrm{n}=$ 64), que cursaban asignaturas asociadas a la enseñanza de las ciencias sociales durante los cursos académicos 19/20 y 20/21. Indagamos en las dimensiones de conceptualizaciones de memoria ${ }^{5}$ y de la experiencia escolar declarada ${ }^{6}$ que hemos trabajado gracias a la aplicación de diversas estrategias de análisis de contenido, de discurso (SANTANDER, 2011), de palabras clave en contexto (ILLIA; SONPAR; BAUER, 2014) y de estadística descriptiva.

A su vez, nos acercamos al estudio de las narrativas del currículum desde la transición democrática, enfatizando en los que enmarcaron la experiencia educativa de la mayoría del profesorado en formación participante en el estudio. También, procuramos contar con un corpus de libros de texto 7 perteneciente a las distintas legislaciones estudiadas e incidiendo con mayor detalle en las usadas por el futuro profesorado en su experiencia como estudiantes de educación secundaria ${ }^{8}$. Estos materiales fueron analizados a partir de sus

\footnotetext{
${ }^{4}$ El cuestionario estuvo compuesto por 3 dimensiones de exploración: a) conceptualización de la memoria; b) experiencia escolar del aprendizaje de la memoria; y c) formación inicial recibida sobre memoria. Estas dimensiones se articularon en 13 ítems: 5 preguntas cerradas de identificación; 4 preguntas abiertas sobre conceptualizaciones de la memoria; y 4 preguntas cerradas, 2 de ellas tipo Likert que exploran, por un lado, los periodos a los que asocia la memoria y, por otro, la percepción que tienen respecto a su futura práctica docente con estos temas. Las otras 2 preguntas fueron de opción múltiple cualitativas e indagaron en las metodologías y recursos empleados en la escuela para el trabajo de la memoria histórica.

${ }^{5}$ Pregunta 7: “¿Podrías decir qué entiendes por memoria histórica?” Pregunta 8: “¿Consideras que es importante trabajar la memoria histórica en la escuela? ¿Por qué lo crees eso?” Pregunta 9: "De 1 (poco) a 4 (mucho) indica cuánto se relaciona la memoria histórica con los siguientes procesos: Segunda República, Guerra Civil, Franquismo, Transición Democrática y Democracia." Pregunta 13: “¿Sabes algún hecho histórico que se pueda enmarcar en la memoria?”

${ }^{6}$ Pregunta 10: “Cuando estabas en la educación secundaria, ¿usabas libros de texto? ¿Recuerdas cual?” Pregunta 11: "Indica si en la escuela aprendiste sobre memoria a través de: la explicación del profesor, el libro de texto, actividades creadas por el profesor, otras actividades como visionado de films o salidas a museos."

La lista de los libros de texto y currículums analizados se puede consultar en la lista de referencias bibliográficas.

${ }^{8}$ Los datos recogidos sobre las editoriales empleadas por el futuro profesorado en su experiencia escolar son los siguientes: Barcanova: 2,4\%; Cruïlla: 1,6\%; Edebé: 1,6\%; No contesta: 5,2\%; No
} 
dimensiones didácticas (estrategias promovidas) y los contenidos que abordan mediante un análisis de contenido, de discurso ${ }^{9}$ y de coocurrencias ${ }^{10}$.

Con esta metodología, articulamos el texto en una serie de apartados que exploran las distintas dimensiones de nuestro estudio, comenzando por el papel que tiene el trabajo de la memoria en las sociedades democráticas, a partir de lo cual reflexionamos sobre el papel que juegan los libros de texto en las construcciones de las narrativas (en general) y de la memoria (en particular). A continuación, abordamos algunas relaciones entre historia investigada e historia enseñada, centrándonos en nuestra temática. Posteriormente, exploramos las percepciones sobre la importancia que tiene el trabajo de la memoria en la visión del futuro profesorado, para seguidamente delinear una relación entre la experiencia escolar con las construcciones de memoria. Se aportan algunas reflexiones finales que proyectan los resultados de este estudio tanto a la historia enseñada como la historia investigada.

\section{Ciudadanía, memoria y enseñanza de Historia}

En las últimas décadas, ha habido un interés general en la formación de ciudadanos democráticos que ha estado cada vez más presente en la formación del profesorado, a la vez en las instituciones públicas (BIESTA, 2016). Es una formación que apuesta progresivamente por abandonar los contenidos cívicos y enfocarlos al trabajo de la vida cotidiana y la participación en sociedad (BIESTA, 2016). En el caso de España, esta idea se ve materializada en la actual normativa curricular, en la denominada competencia social y ciudadana, que permite al individuo plantear y resolver problemas, comprender para actuar, fomentar la racionalidad y la comunicación (SANTISTEBAN, 2009).

\footnotetext{
recuerda: 51,6\%; No usó: 3,6\%; Santillana; 3,6\%; Vicens Vives: 30,6\%.

${ }^{9}$ Para ello clasificamos la información en las siguientes categorías: Dimensión didáctica, asociada a las indicaciones de trabajo del alumnado; Memoria, que incluyó diversos temas asociados a la memoria, como las víctimas, el exilio, los fusilamientos, entre otros; y Periodo histórico al que se vinculaba: Segunda República, Guerra Civil, Franquismo, Transición democrática y Democracia.

10 Aquí se aplicó, principalmente, el método Reinert (ILLIA; SONPAR; BAUER, 2014), mediante el cual de manera descendiente se determinan clústeres semánticos que configuran corpus determinados por la relación de coocurrencias entre los distintos componentes lexicales.
} 
Esta formación educativa ha ocupado una parte relevante de las investigaciones en el ámbito de la Didáctica de las Ciencias Sociales (GÓMEZ; LÓPEZ; RODRÍGUEZ, 2019). A nivel de currículum y aula, se asocia a las políticas europeas de educación para la ciudadanía democrática, especialmente impulsada por la Unión Europea que se contrapone epistemológicamente a los totalitarismos que dieron lugar a parte importante de las memorias del siglo XX. La mirada europea sobre la ciudadanía que se espera promover se fundamenta a su vez en un importante sentimiento de identidad transnacional, que encuentra parte de sus antecedentes en la memoria (SIERP, 2014). La idea de identidad global y europea busca reactivar el sentimiento de pertenencia a una realidad transnacional (GARCÍA; DIESTRO, 2013), esperando confeccionar una identidad colectiva, ya sea desde la herencia del pasado o a partir de la representación e identificación de los propios colectivos (GARCÍA; DIESTRO, 2013).

A partir del papel histórico que han tenido los conflictos en la configuración de las identidades en los países europeos y de la aspiración de generar una identidad transnacional, desde el Consejo de Europa, primero o desde la Unión Europea, después se han realizado sistemáticamente mesas de trabajo y se han establecido recomendaciones para promover la educación para la ciudadanía democrática europea y los derechos humanos (PINGEL, 2003). Incluso, han llegado a publicar materiales docentes con una mirada "paneuropea" que obvien los prejuicios, sesgos y con miradas conciliatorias (FOSTER, 2011). Así, se ha buscado concienciar a las nuevas generaciones sobre una identidad compartida, que les capacite para asumir sus responsabilidades como ciudadanos de Europa y reconocer el valor de una cultura, de un patrimonio y de una historia común y actuar en consecuencia para una convivencia democrática.

Este vínculo entre memoria e identidad -relevante en los objetivos de la educación para la ciudadanía en Europa desde los años noventa- parece haber calado parcialmente en el futuro profesorado, especialmente como constructor de identidades. Para ellos, la memoria es

[...] la capacidad de establecer conexiones de hechos y acontecimientos del pasado para darles una explicación y significado, y en especial para dar sentido a nuestra identidad colectiva y nuestro presente. (D36, 2020) 
Como se observa, se omite la idea transnacional, pero se manifiesta la relación entre pasado e identidad en tanto pertenencia a un colectivo (HALBWACHS, 1995). De la misma manera que lo hace el futuro profesorado, la dimensión europea de la ciudadanía o los derechos humanos en los contenidos curriculares o de los libros de texto asociados la historia del siglo XX español, no están demasiado presentes ${ }^{11}$. El énfasis que vemos en los materiales que guían la práctica educativa, si de identidad se trata, está situado en la de colectivos nacionales, y en el caso catalán, reforzando la singularidad de la comunidad autónoma12. Esto explicaría, en parte, las razones por las cuales el estudiantado de formación de profesorado asocia con más intensidad la memoria a la identidad personal o de colectivos reducidos ${ }^{13}$, en lugar de la mirada transnacional que se ha impulsado desde Europa, como ya se había advertido años atrás (PRATS, 2001).

En consecuencia, a pesar de los esfuerzos de superar la visión local de los procesos de memoria para darle un enfoque ciudadano, al menos por parte de las directrices y recomendaciones de Europa, la memoria histórica sigue confeccionando parte de la identidad local como base para el sentimiento de pertenencia a un colectivo determinado, indisolublemente relacionada con la dimensión social en una perspectiva temporal concreta (HALBWACHS, 1995). Allí, lo histórico y social operarían como causas de memoria y no como contextos de memoria (ARÓSTEGUI, 2004) que movilizarían la cohesión de la ciudadanía, pero no necesariamente su trabajo para una acción democrática.

Pero, al tratarse de construcciones sociales, los procesos de recuperación/construcción de memorias dependen de diversos aspectos como los éticos, los políticos o los culturales (BLOCH, 1925), que marcan qué y a

\footnotetext{
${ }^{11}$ Un estudio que contiene con mucho detalle la presencia de Europa y la dimensión europea en los currículos y los libros de texto es Prats (2001).

12 Por ejemplo, en el texto escolar de 2012, con el que estudió el futuro profesorado encuestado, se señala que en el campo de la cultura:

"En la década de 1960, aprovechando una cierta tolerancia del régimen franquista, se fue construyendo en Cataluña un movimiento cultural y cívico en defensa de la lengua y la cultura catalana, que tuvo un fuerte apoyo social.

Así se empezaron a publicar revistas culturales en catalán (Serra d'Oro y Cavall Fort), se iniciaron proyectos editoriales (Edicions 62) y obras colectivas emblemáticas como la Enciclopèdia Catalana, iniciada en 1969" (GARCÍA; GATELL, 2012, p. 269, nuestra traducción).

${ }^{13}$ La memoria "forma parte de nosotros, de nuestra historia y nos permite resolver preguntas de nosotros" (D85, 2020).
} 
quiénes recordar. Esto es especialmente significativo cuando quien recuerda son las instituciones políticas. Más importante es cuando recaen en la generación de nacionalismos a partir de la manipulación selectiva de las memorias (OLICK; ROBBINS, 1998). Es por ello que diversos historiadores y didactas defienden la incorporación de la memoria histórica en el aula como un recurso para combatir las manipulaciones institucionales de la historia escolar o las saturaciones de la memoria basada en el horror (PRATS, 2020). De este modo, por ejemplo, son lugares comunes de memoria el Holocausto, aunque más concretamente la Shoah, o los fusilamientos durante la Guerra Civil o los primeros años del Franquismo. No forman parte explícita otros procesos sociales y estructurales que van más allá de las memorias de un tiempo "corto" (JELIN, 2013), como, por ejemplo, las construidas por las mujeres o el colectivo migrante.

Para Benjamin (2007), las memorias han de despertar una conciencia crítica que rescate el pasado olvidado14, deviniendo en el "nunca más" (como deber de la memoria de recordar para no olvidar) tan presente en los proyectos de memoria de Brasil, Argentina, Chile (HUYSSEN, 2004; SILVEIRA, 2016) o Colombia (ARBOLEDA-ARIZ; PIPER-SHAFIR; VÉLEZ-MAYA, 2020). Pero esta mirada crítica al recuerdo y al olvido implica también revisar los sujetos constructores de memorias y la construcción de esas memorias de los sujetos y colectivos, para superar la visión victimizante del horror (JELIN, 2013). Un ejemplo de lo que podrían ser estos procesos críticos de memoria es la articulación de los colectivos Historias Desobedientes en Argentina, primero, y Chile, después, conformados por familiares de genocidas que luchan por la memoria, la verdad y la justicia ${ }^{15}$. En España, este tipo de procesos está en vías de desarrollarse. Sin ir más lejos, aun se adolece de procesos institucionales fuertes de reparación de víctimas, así como de una política nacional de búsqueda de desaparecidos o la

\footnotetext{
14 A principios del siglo XXI se hizo latente el debate de memoria versus olvido, donde diversos autores como Ricoeur o Todorov quisieron desmarcar la historia científica de la memoria social, muy institucionalizada e influenciada por los traumas históricos de medianos y finales del siglo XX. Nora (2018), uno de los principales referentes marca un punto de inflexión al considerar la historia como ente científico que tiene en cuenta la memoria, pero remarcando que la historia no se reduce a ella, sino que tiene en consideración todos los elementos que rodean a un suceso histórico.

15 Ver página del colectivo argentino en https://www.facebook.com/DesobedientesHi/ y del chileno en https://www.facebook.com/HistoriasDesobedientesChile/.
} 
construcción de museos de memoria (BARREIRO, 2017) que aun polariza y pervive en la sociedad.

Si consideramos que los sistemas educativos son reflejo del contexto social (ARENDT, 1996), a la vez que reproducen intereses hegemónicos (BOURDIEU, 1983), no es de sorprender que la idea de recordar para no olvidar, o la memoria para el nunca más, esté relativamente ausente en las narrativas de los libros de texto y en las directrices curriculares. Así, se dificulta la construcción de una visión crítica de la memoria que deviene, más bien, en la idea del recordar para no repetir que tiene el profesorado en formación ${ }^{16}$.

"Recordar para no repetir" significa armar un relato fáctico de lo
ocurrido y transmitirlo. En los períodos post violencia, después de
las catástrofes sociales, cuando la magnitud y naturaleza de lo
ocurrido todavía no están sistematizadas o encuadradas en una
narrativa con sentido, se requiere una etapa de organización de
datos fácticos, de elaboración de un relato de lo ocurrido. Paso
previo a cualquier estrategia de transmisión (JELIN, 2013, p. 139-
140).

Las narrativas del futuro profesorado dan cuenta del momento seminal que existe en España sobre el trabajo de la memoria, en la que tienen un papel relevante las narrativas visuales y audiovisuales (JELIN, 2013). Es significativo, que parte de la experiencia escolar del futuro profesorado, haya trabajado estos temas a partir del visionado de films u otros registros audiovisuales (68,3\%).

Cabe preguntarse, entonces, ¿qué posición tendría que asumir la historia como disciplina y como materia escolar? Para Ricoeur,

[...] a la historia le corresponde el poder de ampliar la mirada en el espacio y el tiempo, la fuerza de la crítica en el orden del testimonio, explicación y comprensión, el dominio retórico de los textos, y más que a nada, el ejercicio de la equidad respecto de las reivindicaciones de los distintos bandos de memorias heridas. (RICOEUR, 2007, p. 27)

\footnotetext{
${ }^{16}$ El 34,3\% del estudiantado participante en nuestro estudio remiten a la idea de recordar para no cometer los errores del pasado. Algunas citas ilustrativas de este grupo son las siguientes: la memoria sirve "para saber de dónde venimos; para evitar cometer errores del pasado" (D248, 2020) y "es importante que las futuras generaciones tengan conocimiento de todo lo que ha sucedido a lo largo de la historia. Está en sus manos utilizar este saber para no repetir errores perjudiciales para la humanidad" (D182, 2020).
} 
Por tanto, la historia como entidad científica tiene en cuenta la memoria, pero se diferencia de ella debido a que tiene en consideración todos los elementos que rodean a un suceso histórico desde una perspectiva científica (PRATS, 2020). Así, se revindica la memoria desde una perspectiva histórica y crítica que permita asentar los valores democráticos y fomentar una ciudadanía crítica libre de pensamiento. En este sentido, la memoria enseñada no puede circunscribirse simplemente al conocimiento episódico de ese pasado traumático, basado en el horror, sino que es necesario interpelarlo, cuestionarlo y dotar de historicidad a los distintos sujetos, reconociendo el terreno de disputa que implican los procesos de memoria. En otras palabras, los profesores e historiadores han de reconstruir y normalizar la memoria a través de la historia, para así evitar su posible manipulación. La misión del historiador y del profesor es trabajar el presente y luchar contra la presión de las memorias (PRATS, 2020).

En la relación entre historia investigada e historia enseñada, donde la primera opera como referente disciplinar para la segunda (PRATS, 2016), los debates que aun alberga la historia reciente, no facilitan realizar la transposición didáctica. El camino en desarrollo sobre el debate de las temporalidades de la historia reciente, sus conceptualizaciones y los enfoques metodológicos apropiados (LEVÍN, 2017), son cuestiones que también deben abordarse desde la didáctica para un trabajo científico de estos procesos. A la vez, al decir de Flores y Silingardi (2016), la historiografía debe superar los negacionismos, las simplificaciones, las asimilaciones peligrosas, las represiones, las reparaciones morales o las comparaciones jerarquizadas.

En cualquier caso, desde un punto de vista educativo, es de especial relevancia reivindicar las construcciones históricas de carácter científico vinculado con los avances en los estudios históricos y de memoria, en desmedro de los constructos narrativos articulados en procesos institucionales y selectivos. La transmisión de una sola memoria legitimada por el Estado es contraproducente en la construcción de una ciudadanía activa y democrática, en esencia, plural (JELIN, 2013). La formación de los docentes, inicial y continua, debería incidir en estas dimensiones cuando las instituciones no estructuran bases didácticas que incluyan estos enfoques de manera suficiente, con tal de 
ampliar la mirada desde la escuela para incorporar sujetos, temporalidades, generaciones y espacios diversos en la construcción de las memorias (SACAVINO, 2015) y limitar la transmisión de un recuerdo seleccionado (TRAVESO, 2007).

Ha de evitarse construir memorias hegemónicas unidireccionales, enmarcadas sólo en la historia oficial, y se debe apostar por una proliferación de memorias (FLORES; SILINGARDI, 2016), intentando no llegar a su sobresaturación (HUYSSEN, 2004). Desde el punto de vista educativo, deberíamos, pues, dirigirnos hacia una didáctica crítica, que busque comprender las formas en que ese pasado a llegado a nosotros y buscar la problematización de la historia y del presente en la que el profesorado y el estudiantado sean agentes de esta historia. Esto implica que la historia como materia escolar ha de aspirar a crear un conocimiento libre e independiente del poder estatal (CUESTA, 2011, p. 22), potenciando su uso público o "dimensión pública en la formación de la identidad democrática de los ciudadanos", que sin duda es favorecido por el trabajo escolar de la memoria, al despertar una conciencia histórica para la democracia.

Trabajar las memorias individuales y colectivas en aula fomenta el desarrollo de habilidades que permiten conocer el conflicto social y político (JIMÉNEZ; INFANTE; AMANDA, 2012). Aquí el de las memorias individuales debe entrar en relación con la memoria colectiva (GARCíA, 2020) a través de estrategias educativas como "la construcción de álbumes, portafolios de la memoria y líneas del tiempo que combinan lo personal-familiar con lo localnacional” (GARCÍA, 2020, p. 28).

Esta idea, si bien está ausente de la historia enseñada en los currículums y los libros de texto, aparece en algunos casos en los relatos del futuro profesorado, aunque no de manera mayoritaria. Algunas narrativas recogidas sostienen que se debe "buscar un pasado [que] es el recuerdo de aquellos momentos que han sido importantes y tanto puede ser por la historia de la humanidad como para tu historia personal" (D94, 2020), puesto que la memoria y la historia "es la conciencia del pasado propio a una persona o colectivo" (D234, 2020). Estos ejemplos denotan un cierto grado de consciencia sobre la formación y resignificación de la memoria en el individuo a través de sus interacciones con los diversos agentes sociales; pero, debido a la ausencia total de estos elementos 
en los libros de texto y en las legislaciones, sería indicativo de que el origen de estas ideas se encuentra fuera del aula ${ }^{17}$.

Uno de los factores que podría permitir comprender estas construcciones al margen del aula es el papel que han tenido los medios de comunicación y las activaciones patrimoniales, pues establecen un gran número de configuraciones simbólicas que influyen en la conciencia de los grupos (SOLA, 2013). En este modo puede afirmarse que:

[...] las películas, los programas televisivos, los diarios y las revistas, a pesar de ser objetos que normalmente son consumidos en forma privada, se han convertido en la interfaz que conecta las vivencias y los sentimientos personales con las experiencias y las emociones compartidas de manera grupal (HERNÁNDEZGUTIÉRREZ, 2019, p. 11).

Por otro lado, las efemérides, las restauraciones patrimoniales, la museística y las celebraciones son un elemento fundamental para crear una determinada imagen del pasado ${ }^{18}$.

A nivel educativo, esto supone dos cuestiones: por una parte, permite discriminar qué rasgos de la memoria corresponderían a las construcciones "privadas", en este caso, la consciencia del papel de la memoria como constructora de significaciones y resignificaciones antes mencionada y, por otra, plantea el desafío de incorporar en su práctica, competencias como la mediática y la social ciudadana, relegando en un segundo plano la tradicional visión narrativa como sucesión de hechos de la historia reciente, donde la memoria sirve, principalmente, para reconstruir los horrores de las víctimas.

\section{Los libros de texto y las construcciones simbólicas}

Cuando hablamos de sistemas educativos y de lugares de memoria (o lieux de memoire en términos de Pierre Nora), es imprescindible remitir a los libros de

\footnotetext{
17 En los casos antes citados, que presentan una visión más crítica de la memoria, integrando lo local y lo global, también aparecen una conceptualización muy restringida respecto de los procesos que dan lugar a la memoria: la Guerra Civil y el Franquismo, de la misma manera que la gran mayoría de las respuestas del futuro profesorado.

18 La memoria histórica se entiende como "una serie de eventos que han realizado un impacto muy potente en el pasado de tal manera que tienen efecto en las vivencias del presente. Es por ello que ciertos actos históricos se conmemoran de alguna forma" (D173, 2020).
} 
texto, puesto que tienen una trayectoria casi tan larga en la formación de las jóvenes generaciones, como la formalización de esta enseñanza; a la vez que un papel protagónico, como recurso, en ocasiones casi único, en los procesos de enseñanza-aprendizaje.

Los libros de texto fueron herramientas de los Estados-Nación modernos con el objeto de formalizar, homogeneizar saberes y conocimientos comunes, especialmente asociados a la nación y su identidad (FUCHS; HENNE, 2018). Pero no fue hasta el siglo XIX, con la masificación del sistema educativo y el fortalecimiento de los nacionalismos, que adquirieron un alcance mayor en la población (SAMMLER, 2018).

Poco a poco, los libros escolares formaban parte simbólica y material de la cultura escolar y su contenido contribuía a la articulación de narrativas únicas. No es gratuito, entonces, que tras la Primera Guerra Mundial, y especialmente tras la Segunda Guerra, diversas comisiones europeas centraran sus esfuerzos por observar desde un punto de vista comparativo -especialmente entre pueblos vecinos- la manera en que eran tratados mutuamente (FUCHS; HENNE, 2018). Tampoco lo es que fuese un tema sistemático de debate en el Consejo de Europa sobre la educación europea orientada a solventar conflictos nacionales (PINGEL, 2003); o que, naciese el Georg Eckert Institut para la investigación en libros de texto (FUCHS; HENNE, 2018) orientado al estudio de pasados conflictivos compartidos en la línea de promover un entendimiento internacional. De esta manera, se reconoce el papel relevante que tienen estos materiales en la configuración simbólica de la joven ciudadanía en etapa escolar.

Su influencia en las conceptualizaciones que promueven, aunque no de manera exclusiva, radica en que son transmisores de narrativas elaboradas y en que reflejan la construcción histórica de la propia cultura de aula. Los factores que inciden en su elaboración, complejos y diversos, continúa siendo influenciada por las tensiones "entre el conocimiento especializado y la pedagogía, entre el control del estado y las exenciones de requerimientos aprobados, entre el privilegio, el monopolio estatal y el libre mercado" (SAMMLER, 2018, p. 14, nuestra traducción). 
Sea cual fuere el caso, su vasta presencia en el sistema educativo pone de manifiesto que la centralidad del libro de texto tendría como consecuencia inmediata una amplia circulación de sus discursos. Al mismo tiempo, denotaría la legitimidad atribuida, por la razón que fuere, a la construcción del saber histórico a enseñar en la escuela. Sin ir más lejos, los libros de texto en España representan la tercera tipología con más peso en el mercado editorial, aun a pesar de su decrecimiento en los últimos años (SECRETARÍA GENERAL TÉCNICA, 2018). Si se considera que en España el libro escolar está regulado, desde hace algunos años, por las preferencias de los centros educativos o del profesorado ${ }^{19}$, su presencia relevante en el mercado editorial es ilustrativa del peso que conserva en la cultura escolar.

En este estudio, más del 90\% de los estudiantes encuestados declararon haber empleado libro de texto para el aprendizaje de la historia reciente y la memoria, mientras sólo un 8,7\% no contestaron o declararon no haberlos usado. Resultados semejantes fueron recogidos en la Región de Murcia por Gómez, Rodríguez y Mirete (2017, p. 244), donde el 87\% del estudiantado están en algún grado de acuerdo con que "el profesor se centraba principalmente en los contenidos históricos del libro de texto". Conclusiones semejantes las observamos en el estudio de Martínez (2014, p. 46) quien, específicamente para el tema de la transición democrática señaló que los libros de texto son el material predominante y "generalmente son seleccionados por el docente atendiendo a sus contenidos históricos y muy pocas veces se consideran sus principios metodológicos o sus finalidades didácticas".

En consecuencia, no son gratuitos los diversos usos que hace el profesorado de estos recursos como ya advertían Martínez, Valls y Pineda, al señalar que es

[...] un medio que "va más allá de los procesos de aula" y se incardina en la vida del alumnado y profesorado como un símbolo con el que se contrastan informaciones o sencillamente aparece junto a lo "habitual de las clases" formando parte de su apariencia cotidiana. (MARTÍNEZ; VALLS; PINEDA, 2009, p. 31)

\footnotetext{
19 Cabe destacar que entre los años 1970 y 1990, los contenidos de libro de texto en España pasaban por una censura administrativa que velaba por la relación estrecha entre los contenidos de los libros y el currículum.
} 
Para los autores, su empleo en el proceso didáctico se circunscribía mayoritariamente al aula, ya sea mediante copia, subrayado, actividades, entre otras y, secundariamente a otras acciones como la planificación de contenidos o evaluación.

No cabe duda, por tanto, que el libro de texto es un material muy vigente y una de las principales maneras con las cuales se abordan los procesos históricos recientes. Otra cuestión diferente es el peso real que tengan en la educación histórica de los estudiantes a la hora de construir su visión del pasado. Algunos estudios han constatado una influencia en la contextualización y la estructuración de la historia escolar, pero con una limitada profundidad en esa construcción del pasado (BELLATTI, 2018). La propia fisionomía que tienen los libros de texto, en los que se ofrece una escasa problematización de la Historia (SÁIZ, 2013), también la observamos en nuestros datos. La mirada crítica a los procesos de historia reciente y memoria, a la inclusión de múltiples perspectivas en su tratamiento, al trabajo con fuentes apropiadas o a la generación de una mirada sistemática (PRATS, 2016) es muy minoritaria. En todo el corpus de libros de texto analizados (1980-2019), sólo un 8\% de las actividades -que son en definitiva los espacios textuales para la construcción activa del conocimiento-, se promueven algún rasgo del pensamiento histórico ${ }^{20}$, a la vez que un 9\% de ellas inciden en la construcción de aprendizajes a partir de fuentes de información (paratexto) diferentes a las del texto ${ }^{21}$. La mitad de todas las actividades analizadas, fomentan aprendizajes de carácter declarativo ${ }^{22}$ o, expresado en otros términos, lo hace a partir de la descripción cronológica de hechos o periodos pasados.

\footnotetext{
20 Ejemplo: "Supongamos que durante la Guerra Civil estuviste en una de las grandes batallas (Brunete, batalla del Ebro, frente de Aragón) y, al cabo de veinte años, te encuentras con una persona que estuvo en la misma batalla, pero en el lado contrario: Intenta reconstruir la conversación. Tienes libertad para imaginar la vida que cada uno de ellos ha vivido desde entonces, pero la conversación debe centrarse en sus recuerdos, en los años que has estudiado en esta unidad" (SANTACANA; ZARAGOZA, 1997, p. 170).

${ }^{21}$ Ejemplo: Libro de texto de 2003: "1. Analiza las fotografías. Los efectos de la guerra: la población civil. Para analizar las fotografías de la derecha, sigue estos pasos: [se enumeran los pasos]" (GARCÍA, 2003, p. 234, nuestra traducción).

22 Ejemplo: "1. Sintetiza las etapas y los eventos principales del conflicto bélico, haciendo una mención especial de los acontecimientos de Cataluña. 2. ¿Qué consecuencias tuvo la guerra para la población española?” (GARCÍA; GATELL, 2012, p. 225, nuestra traducción).
} 
En este sentido, al menos en las secciones dirigidas trabajar aprendizajes (actividades), muchos libros desaprovechan su potencial formativo y, por tanto, coincidimos con Díez Gutiérrez (2020) en que el trabajo de la memoria en las aulas y en los libros de texto requiere ser fomentada desde una visión crítica a nivel de contenido histórico y a nivel didáctico. Reconocemos que este deber de memoria va más allá de los libros de texto. El marco legislativo debe ofrecer unas directrices de trabajo precisas que permitan orientarla de forma efectiva en el aula.

Al explorar en una mirada de mayor duración los énfasis curriculares vemos una evolución, pero todavía insuficiente. Desde que la memoria apareciese explícitamente en los currículums su presencia ha sido vaga e imprecisa. El énfasis se puso en el papel de las instituciones democráticas (en 1991), en la relación entre la historia personal y local en temas de historia reciente (en 2007) ${ }^{23}$ o las nociones temporales más amplias que vinculan las continuidades y los cambios (en 2015) ${ }^{24}$, adoleciendo de un posicionamiento didáctico que permita situarla temporal y espacialmente o darle un sentido formativo a la historia del tiempo presente. Ante este escenario, los libros de texto subsanan de alguna manera las ausencias del currículum, al incorporarla, y ponen en manos del profesorado su profundización. De aquí que sea relevante indagar en las conceptualizaciones que éste tiene, puesto que si fuera cierto que "el profesorado podría preferir libros de texto que siguen las aproximaciones dominantes o negociadas opuestas a las que estimulan el pensamiento crítico" (BLÄSI, 2018, p. 84, nuestra traducción), entonces la tarea es más urgente.

\section{Historia enseñada y las conceptualizaciones de la memoria}

Como señala Cuesta (2002), la historia enseñada ha recorrido un camino muy distinto al de la historia investigada. El punto de inflexión lo localiza en el siglo XIX, con la emergencia de lo que el autor denomina el código disciplinar,

\footnotetext{
23 "Comparar los regímenes autoritarios y democráticos. Conocer aspectos del franquismo y de la transición democrática en Cataluña y España que permitan identificar el papel de las individualidades como sujetos de la historia y la necesidad de preservar la memoria histórica" (CATALUÑA, 2007, nuestra traducción).

24 "Los vínculos entre presente y pasado: continuidades y cambios en la Europa del siglo XX al XXI"; "Resolución de conflictos. Función de la memoria histórica" (CATALUÑA, 2015, nuestra traducción).
} 
compuesto por los saberes escolarizados nutridos de las disciplinas de referencia, pero arcaicos, nacionalistas, elitistas y memorísticos. En sus palabras, este código

[...] es el complejo resultado de una metamorfosis y una recontextualización de la cultura dominante merced a la interrelación de varios factores: la función atribuida a los estudios históricos en los distintos niveles educativos (que, no se olvide, eran ocupados por clases sociales desiguales), las regulaciones jurídicas y, sobre todo, la interacción en la práctica cotidiana de los textos visibles (programas y manuales) con los contextos escolares, interacción que aparece mediada de manera crucial por la condición de clase y género de los destinatarios y las señas de identidad del campo profesional de los docentes. En la intersección de discursos y prácticas institucionalizadas, vino a darse esa peculiar alquimia cultural que crea la historia escolar. (CUESTA, 2002, p. 234)

Los saberes históricos formalizados en la escuela del siglo XIX, de carácter enciclopédico, siguen vigentes en la actualidad, ya sea por el peso que tienen en el currículum o por las características de la elaboración de libros de texto. Observamos una didáctica predominantemente basada en la descripción narrativa de los hechos y su identificación y en la explicitación de personajes, cuando de política se trata ${ }^{25}$. También observamos una escasa incidencia de saberes procedimentales que fomenten la generación de una visión científica y comprensiva de la Historia (PRATS, 2016), como bien ha defendido la didáctica de la Historia desde hace casi medio siglo.

Los libros de texto sitúan la memoria en los procesos de historia reciente de la misma manera que ha sido construida desde la sociedad civil y las políticas de memoria: la Guerra Civil y el Franquismo26 (JELIN, 2013). Más concretamente, lo hacen a partir de algunos hechos concretos que remiten al horror sufrido por la ciudadanía, como es el caso del exilio, las víctimas de la represión o los

\footnotetext{
${ }^{25}$ Por ejemplo, señala un texto del año 2016 que

[...] "en Cataluña fueron juzgados en consejo de guerra unos 78000 catalanes; se ejecutaron 4000. Entre las víctimas de la represión estuvo el presidente de la Generalitat, Lluís Companys. El año 1940 los nazis lo detuvieron en Francia, donde se había exiliado, y lo llevaron a las autoridades franquistas, que lo juzgaron en consejo de guerra y lo ejecutaron en el castillo de Montjuic (15 de octubre de 1949)" (GARCÍA, 2016, p. 273, nuestra traducción, destacado del autor).

${ }^{26}$ El porcentaje de codificación del texto y el paratexto de los libros analizados que contienen aspectos de memoria (exiliados, víctimas, bombardeos, etc.) según periodo histórico es el siguiente: la Segunda República: 4,76\%; la Guerra Civil: 58,73\%; el Franquismo: 31,75\%; la Transición democrática 0\%; la Democracia 4,76\%.
} 
bombardeos de la ciudad de Barcelona en la Guerra Civil. Como se puede ver en la Figura 1, temáticas asociadas a la reparación de víctimas, (como el reconocimiento de la existencia y búsqueda de fosas comunes o, al menos, el reconocimiento de que hay desaparecidos) son temas que están ausentes con ninguna referencia en los libros de texto.

Figura 1 - Distribución de la frecuencia de codificación de fragmentos asociados a la memoria por periodo histórico tratado en los libros de texto.

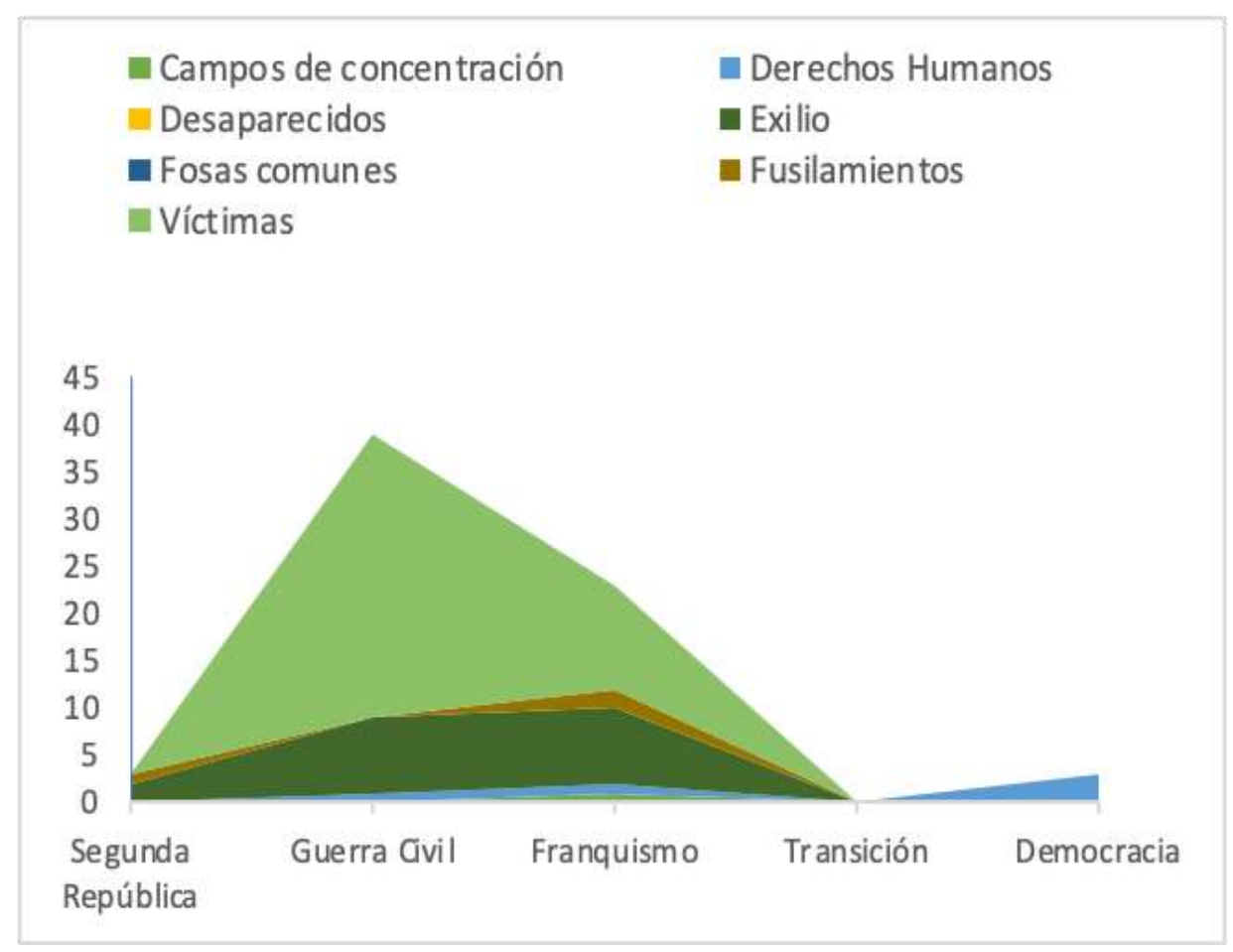

Fuente: Elaboración propia, 2021.

Por tanto, la memoria en los libros de texto se ha construido de manera prioritaria asociada a los sucesos que tuvieron lugar entre la Guerra Civil y el Franquismo, pero ligada con lugares comunes donde destaca el exilio de los republicanos que tienen las presencias más relevantes en los discursos desde el retorno de la democracia ${ }^{27}$. De manera consistente, el futuro profesorado asocia

\footnotetext{
27 Ejemplos: "Redacta una página sobre los efectos negativos de la guerra (muertos, exilio, destrucciones) y documéntala con datos numéricos que encontrarás en enciclopedias y en libros monográficos sobre la guerra civil" (ALBACETE; CUENCA; PARRA, 1981, p. 146). "La guerra causó cientos de miles de muertos y heridos, y desató persecuciones contra los enemigos políticos. Millares de españoles tuvieron que exiliarse para evitar la represión y fue muy elevado el número de presos políticos" (MARTÍNEZ; ROZAS; SECO, 1995, p. 127). "Ante el avance de los insurrectos, cientos de miles de personas abandonaban su casa y se convertía en refugiados" (GARCÍA; GATELL, 2012, p. 223, nuestra traducción).
} 
la memoria a los mismos procesos que los libros de texto, como se puede ver en la nube de palabras (Figura 2) al preguntar por un hecho, proceso o periodo vinculado a la memoria.

Figura 2 - Nube de palabras de procesos asociados a la memoria.

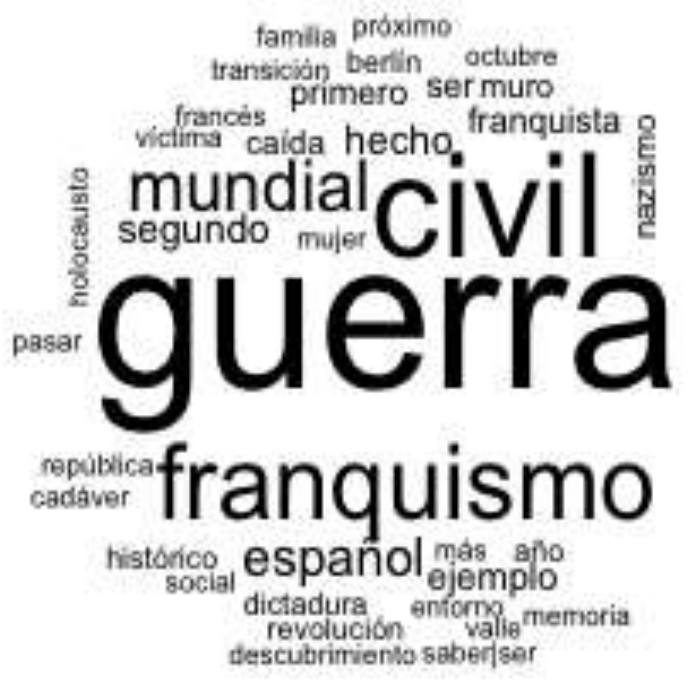

Fuente: Elaboración propia, 2021.

Observamos una continuidad entre las conceptualizaciones que muestra el futuro profesorado, los procesos sociales sobre la recuperación de la memoria y las narrativas de los libros de texto. Narrativas que son cristalizadas en un pasado muy concreto, en la que participó una tipología de personas, también determinada y que padecieron unas vulneraciones específicas: personas que tuvieron que exiliarse producto de la Guerra Civil y la posguerra.

La mirada que existe sobre la memoria en los libros de texto, salvo por la aparición de la sociedad civil en tanto víctimas de la guerra, es cronológica, episódica, masculina y basada en la descripción de los hechos de manera sucesiva. Esto ha implicado, en general, continuar dejando fuera de la historia, con algunas excepciones recientes, a colectivos como las mujeres (SAENZ DEL CASTILLO, 2015) o los niños (PINOCHET; URRUTIA, 2016).

A pesar de los esfuerzos curriculares, la memoria como fruto de la historia reciente, aun no consigue despojarse de la construcción histórica sobre el saber escolar de carácter episódico, narrativo y centrado en la dimensión política 
(CARRETERO; LÓPEZ-MANJÓN; JACOTT, 2002) que se replica en las conceptualizaciones que tiene el futuro ${ }^{28}$.

Es imprescindible, por tanto, ampliar la mirada hacia la memoria desde prácticas que cambien estructuralmente las construcciones simbólicas y la historia que le da origen. Por lo tanto, se deben superar, mediante la consciencia y la práctica, los tópicos habituales, una visión unilateral y restringida, para adentrarse en una comprensión profunda que incluya múltiples dimensiones, sujetos y procesos que dan lugar a las memorias de duración corta y estructurales (JELIN, 2013).

\section{Experiencia escolar y narrativas de memoria}

La memoria tiene un gran potencial para desarrollar actitudes críticas y democráticas (LÓPEZ-FACAL, 2011). Pero comportan una serie de dificultades para el profesorado debido a que deben dialogar relatos subjetivos y plurales (MARTÍNEZ, 2014); persiste una distancia entre las conceptualizaciones docentes y práctica educativa (DELGADO-ALGARRA; ESTEPA-GIMÉNEZ, 2017) y es sensible el lugar que tienen estas temáticas en el presente de los agentes involucrados (profesorado y estudiantado) en cuanto a sus intereses $u$ orientaciones ideológicas (CARRETERO; BORRELLI, 2008). De hecho, las conclusiones a las que Llega Banderas al observar las prácticas de aula sobre problemas sociales relevantes son llamativas:

[...] no se ha observado una presencia explícita y programada de diferentes visiones historiográficas, tales como la historia sociocultural o la historia de género, que enriquecerían enormemente el aprendizaje de la historia y facilitarían el desarrollo de habilidades deseables en una sociedad democrática. En la misma línea, consideramos que no se han aprovechado de manera óptima las oportunidades para lograr un aprendizaje del tiempo histórico desde una visión multiperspectiva. Tampoco se ha puesto de relieve en la práctica de aula, aunque sí levemente en las entrevistas, un cuestionamiento de las identidades naturalizadas en el currículo, como es el caso de las nacionales.

\footnotetext{
28 Para el estudiantado, "en una memoria histórica se tratan principalmente la Guerra Civil y el Franquismo, trabajando política, los conflictos bélicos, la ideología, la religión, etc.” (D22, 2020); son "los hechos que pasaron años atrás" (D161, 2020), que "han sucedido a lo largo del tiempo y que, actualmente, podemos recordar y tenemos constancia” (D175, 2020).
} 
Consideramos que la excesiva centralidad en el uso del libro de texto, con los matices observados, así como la falta de una programación didáctica que aborde de manera decidida los problemas socialmente relevantes por medio de las competencias históricas, impiden una construcción crítica del conocimiento histórico. (BANDERAS, 2020, p. 229)

A nivel de discursos, está extendido entre el profesorado en formación que ha participado en este estudio, en que incluir y trabajar la memoria en el aula es muy relevante. Mas, a diferencia de estudios previos en el que se pone de relieve su potencial formativo especialmente en términos de la ciudadanía democrática (BANDERAS, 2020; DELGADO-ALGARRA; ESTEPA-GIMÉNEZ, 2017), el 43,3\% del corpus de respuestas del cuestionario refieren a la configuración individual, al devenir social y como tema a incluir en el sistema educativo, pero está ausente, al menos de manera explícita, la idea de la función de la memoria en la construcción de la ciudadanía.

Figura 3 - Representación del peso de las narrativas sobre la importancia de la memoria en el futuro profesorado.

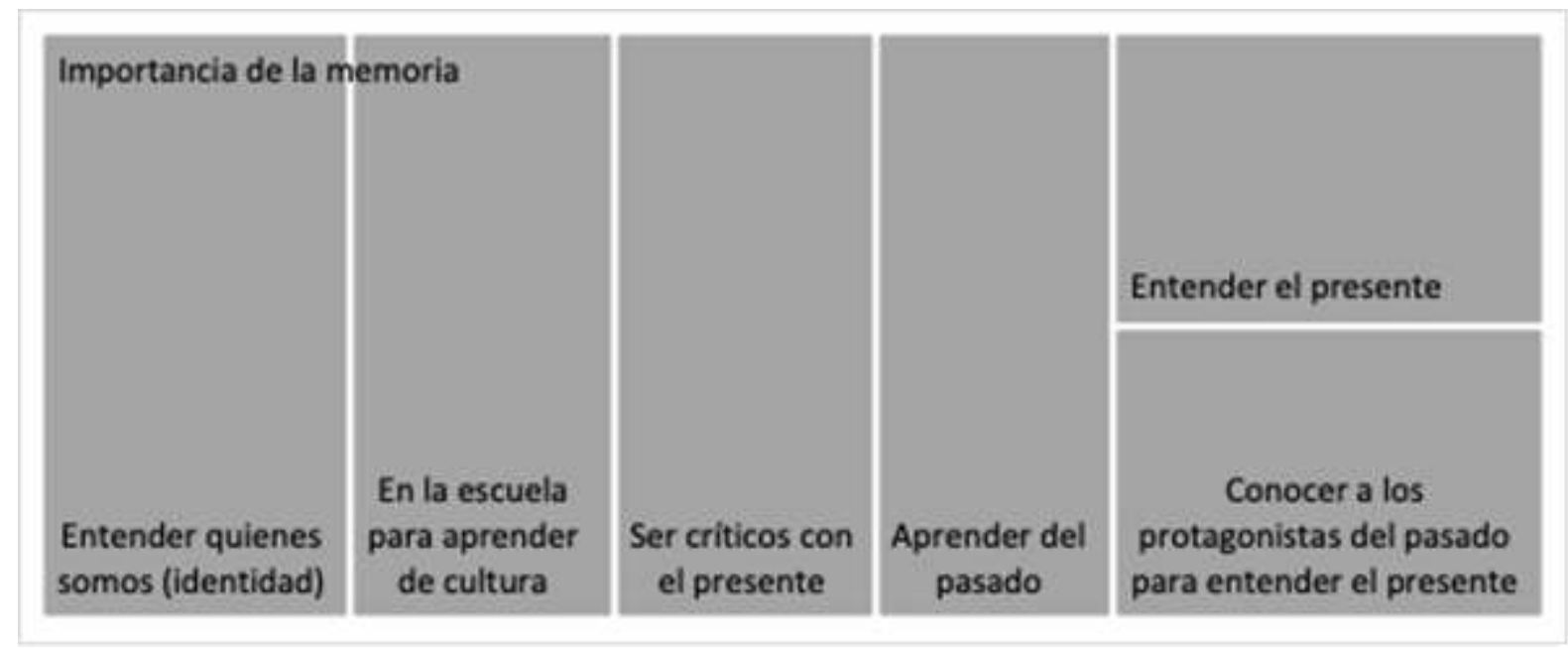

Fuente: Elaboración propia, 2021.

En los relatos, la dimensión ciudadana del trabajo de la memoria y del tiempo presente aparece reflejada sólo entre líneas cuando señalan, por ejemplo, que "permite al niño poder desarrollar un espíritu crítico hacia lo que se está viviendo, y dar respuesta a muchos hechos cotidianos" (D219, 2020) o que "sirve también para intentar entender nuestro presente y ser más críticos" (D23, 2020). 
Esta distancia entre historia reciente, memoria y ciudadanía se observa, a su vez, en los currículums y en los libros de texto y permite suponer que, a nivel de construcción de narrativas, la experiencia previa (escolar y no escolar), o bien el paso por la universidad en asignaturas asociadas a la enseñanza de las ciencias sociales, generó una cierta aproximación que dota a la memoria y la historia reciente de relevancia social y ciudadana. Pese a todo, la ausencia generalizada de relatos que hablen de una dimensión activa de la ciudadanía permite sostener la pervivencia de una narrativa sobre estos periodos asociados a lo cognoscitivo más que a lo ciudadano (PRATS, 2016).

De hecho, al mirar en perspectiva el tratamiento que recibe la historia reciente y la memoria en los libros en Cataluña (que incluye temáticas desde la Segunda República hasta el actual periodo democrático), observamos la reiteración de una mirada centrada en el conocimiento enciclopédico, más que en una problematización que dialogue con el presente. Un ejemplo, lo podemos ver en las consecuencias de la Guerra Civil consignadas en los libros de texto con los que estudió la mayoría del futuro profesorado que respondió nuestro cuestionario (30\%):

La Guerra Civil supuso, para la sociedad española, un gran trauma que tuvo consecuencias importantes a largo plazo:

- Pérdidas demográficas y económicas. A pesar de que no hay unanimidad en el recuento de las víctimas de la guerra, se calcula que el número de muertos está alrededor de 550000.

A esta pérdida, hay que sumar los numerosos exiliados que se vieron forzados a abandonar el país (unos 470.000). A los pocos meses, volvieron a España casi la mitad de los fugitivos. El resto inició un largo exilio en Europa o hacia América Latina.

La guerra también conllevó destrucción de un buen número de infraestructuras y de vías de comunicación. Además, la producción agraria e industrial disminuyó notablemente.

- Pérdida de la democracia y de las libertades políticas. El franquismo implantó una dictadura militar que puso fin a la tradición liberal y parlamentaria iniciada el siglo XIX.

- Ruptura de la convivencia. El enfrentamiento y la violencia dejaron unas heridas en la sociedad española que tardaron en cicatrizarse. La división entre vencedores y vencidos se mantuvo a lo largo de todo el franquismo, que siempre se opuso a cualquier intento de reconciliación entre españoles y el regreso de los exiliados (GARCÍA; GATELL, 2012, p. 255, nuestra traducción).

Dados los relatos secuenciales y narrativos que aparecen en los libros de texto (predominantes en la experiencia escolar), no es de sorprender el valor 
amplio e impreciso que otorga el futuro profesorado a la historia reciente y la memoria, en lugar de incidir en la importancia de su problematización didáctica con tal de formar ciudadanos activos o promover los valores democráticos. La experiencia escolar declarada podría ayudar a matizar estos resultados. Tan sólo el 33\% del futuro profesorado recuerda haber trabajado temas de historia reciente con material creado por su profesorado, cifra que se reduce aún más, al indagar si el trabajo se produjo con fuentes primarias (18,3\%). Como contracara, y al igual que ya ha sido sostenido por investigaciones previas (MARTíNEZ, 2014), el futuro profesorado recuerda en más de un $60 \%{ }^{29}$ de los casos haber aprendido mediante relatos audiovisuales o en itinerarios o museos, evidenciando que las narrativas dadas y elaboradas previamente han sido las principales fuentes de conocimiento para trabajar la memoria en el aula.

No es gratuito, entonces, que este tema haya sido uno de los objetos principales de los estudios en libros de texto (FUCHS; HENNE, 2018). Tampoco lo es que, en el caso de la enseñanza de la Historia, hayan arrojado sistemáticamente las mismas conclusiones: existe una presencia de discursos estandarizados, hegemónicos y, en determinados casos, de cariz nacionalista.

Lo anterior pone en evidencia otra cuestión central a la hora de estudiar las conceptualizaciones sobre ciertos discursos en relación con los libros de texto: su propia naturaleza. Son artefactos diseñados especialmente para construir aprendizajes, o producir cambios cognitivos a través de acciones dirigidas e intencionadas. Las ideas sobre el conocimiento de determinadas temáticas, en nuestro caso de la memoria y la historia reciente, se estructuran a partir de una serie de elementos. Entre ellos, no se puede desconocer la experiencia de aprendizaje mediada por el libro de texto y el profesorado durante los 10 años de educación obligatoria, tiempo que configuraría en parte las construcciones simbólicas sobre la historia. Sin ir más lejos estudios, recientes y no tan recientes, han demostrado contradicciones que derivan en contraposiciones entre discursos progresistas y prácticas tradicionales (GONZÁLEZ; SANTISTEBAN, 2015; ORELLANA; MUÑOZ, 2019).

\footnotetext{
${ }^{29}$ El 68,3\% declararon haber usado productos audiovisuales (películas o documentales) y el 62,7\% indicaron haber hecho itinerarios o haber ido a museos.
} 
Atendiendo al modelo analítico de Williams (2000) y específicamente de la estructura de sentimiento -o dicho en términos breves construidas desde lo individual y colectivo en perspectiva histórica-, las contraposiciones entre discurso y práctica estarían mediadas por experiencia individual, pero también de las generaciones precedentes, las que incidirían en la práctica y los discursos de quienes los emiten. Es aquí donde se vería reflejada otra dimensión de esas construcciones, las asociadas ya no sólo a las maneras de enseñar, sino a cómo se conciben los temas y los conceptos a trabajar en las aulas. Desde este punto de vista, el que un 78\% del futuro profesorado participante en nuestro estudio considerase haber aprendido sobre memoria mediante la explicación del profesor, implica que en sus aprendizajes se verían reflejadas, en parte, las construcciones del profesorado que les formó; lo cual sería, a su vez, reflejo de las propias problemáticas de abordar un tema tan sensible como éste. En este sentido, una de las narrativas llama la atención cuando recuerda que "tenía un profesor de sociales que siempre decía que para evitar que la historia se repita debemos ser conscientes de lo que ha pasado, sino estaremos condenados a repetirla" (D252, 2020).

En el corpus de respuestas de nuestros participantes, la memoria en general aparece como concepto abstracto e indeterminado, confundiéndose a ratos con la propia idea de historia. Como se puede ver en la gráfica siguiente (Figura 4), que resume las temáticas a las que hace alusión el concepto de memoria en el futuro profesorado, observamos que, en la gran mayoría de los casos, está asociada a un pasado identificable - a veces ligado a la construcción de la identidad-y localizable, que no necesariamente tiene influencia en nuestro presente de manera directa, pero sí que ha constituido la sociedad actual. Además, todas las referencias a la memoria y sus elementos constitutivos están mediados por lo que se recuerda y en ninguna de las respuestas recogidas, se hace mención al olvido. La idea selectiva de la memoria que ha sido desarrollada y criticada por la Historia y los estudios de memoria (RICOEUR, 2007) está, por tanto, ausente, lo que denota una construcción parcial del propio concepto. 
Figura 4 - Representación gráfica de los discursos sobre la memoria en futuro profesorado.

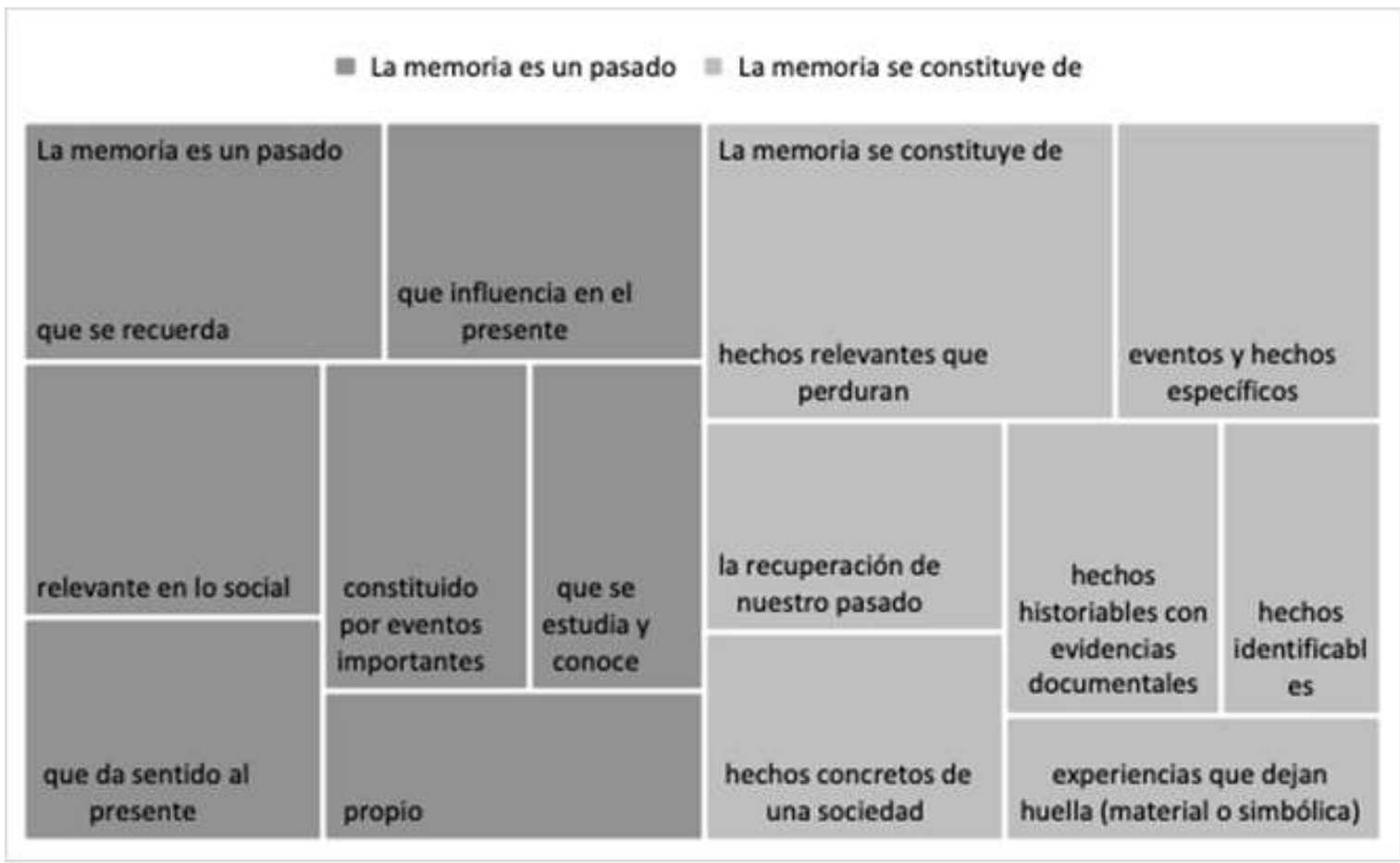

Fuente: Elaboración propia, 2021.

Las ideas expresadas en la Figura 4 son interesantes, puesto que dan cuenta de una idea estática, como algo cristalizado que es objeto de conocimiento, pero escasamente un tema de reflexión o resignificación, como se ha propuesto que debe ser desde las pedagogías de la memoria (SACAVINO, 2015). Tampoco se observa en los relatos menciones al origen conflictivo de los procesos que dan lugar a la memoria (JELIN, 2001), aunque como se ha consignado previamente, se la sitúe principalmente en procesos de Guerra Civil y Franquismo. Así, el futuro profesorado concibe la memoria como un concepto abstracto a ratos diluido con la Historia, que aparece de manera fija y localizada en un tiempo anterior que no nos pertenece. Se aleja, en consecuencia, de una de las características esenciales que distingue Pierre Nora al señalar que es por definición, siempre presente (PRATS, 2020).

Estos datos son consistentes con el enfoque que se ofrece en los libros de texto. La historia reciente aparece narrada de manera descriptiva y cronológica, escasamente problematizada y la memoria, cuando aparece, lo hace a partir del recuerdo de ciertos hechos concretos, que omiten los olvidos, el 
papel en el presente o las diversas dimensiones humanas que las articulan. Así, se presenta de forma invariable y con rasgos estereotipados, que ya han sido criticados por los estudios de memoria (JELIN, 2013; SACAVINO, 2015).

Si consideramos que "los esquemas que organizan el pensamiento de una época sólo pueden ser comprendidos completamente por referencia al sistema escolar, único capaz de consagrarlos y constituirlos, por el ejercicio, como hábitos de pensamiento comunes a toda una generación" (BOURDIEU, 1983, p. 24), la experiencia escolar del futuro profesorado permitiría entender, en parte, la escasa elaboración que se observa en las narrativas sobre la memoria, a la vez que su estereotipación y los vínculos con la identidad ${ }^{30}$.

\section{Apuntes finales}

Tras observar con las relaciones entre conceptualizaciones de la memoria y las narrativas en los libros de texto, podemos observar una serie de las continuidades que interpelan, a la didáctica de la Historia como disciplina de conocimiento y de enseñanza; a la Historia como disciplina de referencia de la didáctica, en cuanto a su función social y usos públicos y a los propios estudios de memoria. Si bien en las disciplinas de conocimiento histórico y de memoria se ha generado un avance significativo y se dispone de un corpus teórico y empírico bastante consolidado, en las aulas y en la didáctica aun queda un camino amplio por recorrer.

El profesorado en formación mantiene una visión ambigua sobre la memoria, siendo en general, incapaz de distinguirla de la Historia a nivel de conceptualización, pero sí que reivindican su importancia e identifican procesos históricos generadores de memoria. Pero presentan una visión estereotipada de ella y cristalizada en dos procesos concretos, escasamente problematizados y menos aún, ligados con la concepción de ciudadanía en sus aspectos cívicos y

\footnotetext{
${ }^{30}$ En este sentido, convendría actualizar el conocimiento que existe en el campo de la didáctica de las Ciencias Sociales sobre las distintas dimensiones que inciden sobre el saber histórico del estudiantado, ya que los estudios disponibles datan de los años 1990 y los escasos estudios que hablan de este saber histórico, demuestran que el papel de la escuela en la construcción de narrativas es parcial. Ver, por ejemplo, los textos de Prats, Valls y Miralles (2015); Carretero y Borrelli (2008); o Carretero, López-Majón y Jacott (2002).
} 
sociales. De esta manera, observamos continuidades entre el papel que ha tenido la experiencia escolar, las narrativas propuestas en los libros de texto y la construcción simbólica que ofrece el futuro profesorado en cuanto a los marcos generales del conocimiento social, aunque su peso y profundidad debe aún ser investigado.

Al mismo tiempo, y a pesar de que ciertas temáticas y sujetos comienzan a aparecer en los libros de texto y en los currículums, ampliando la visión estática de la memoria, las propuestas didácticas son todavía insuficientes y requieren un cambio cultural que dote a la Historia enseñada en la escuela y en la formación inicial docente de códigos simbólicos que superen las herencias de la experiencia escolar de larga duración.

A partir de lo anterior, consideramos que es un imperativo fortalecer el vínculo entre investigación y docencia, especialmente en el trabajo con el futuro profesorado, en tanto reproductor y transformador en el aula, que cambie sus estructuras simbólicas derivadas de la cultura, mediante la consciencia y la práctica. También es esencial que las propias disciplinas de referencia-memoria e historia- reconozcan más intensamente la necesidad de diálogo con la didáctica, que promueva una retroalimentación de perspectivas y enfoques para un trabajo efectivo de la memoria, del conflicto y de la historia reciente.

\section{Referencias}

ARBOLEDA-ARIZA, Juan; PIPER-SHAFIR, Isabel; VÉLEZ-MAYA, Margarita. Políticas de la memoria de las violaciones a los derechos humanos en la historia reciente: una revisión bibliográfica desde el 2008 al 2018. Revista Mexicana de Ciencias Políticas y Sociales, Ciudad de México, v. 65, n. 239, p. 117-140, 2020. Disponible en: https://doi.org/10.22201/fcpys.2448492xe.2020.239.69405. Acceso en: dic. 2020.

ARENDT, Hannah. Entre el pasado y el futuro: ocho ejercicios sobre reflexión política. Barcelona: Península, 1996.

ARÓSTEGUI, Julio. Memoria, memoria histórica e historiografía. Precisión conceptual y uso por el historiador. Revista Pasado y memoria, Alicante, n. 3, p. 15-36, 2004. Disponible en: https://doi.org/10.14198/PASADO2004.3.02. Acceso en: 1 nov. 2020. 
BANDERAS, Néstor. Educar para una ciudadanía crítica: una investigación a partir de los usos y finalidades de la historia escolar. Revista Panta Rei, Murcia, v. 14, n. 1, p. 205-237, 2020. Disponible en:

https://doi.org/10.6018/pantarei.444791. Acceso en: 1 enero 2021.

BARREIRO, Manuel. La memoria histórica en España y su situación en el ámbito educativo: la necesidad de crear un museo memorial en España. Revista Historia Autónoma, Madrid, n. 11, p. 261-278, 2017.

BELLATTI, Ilaria. La comprensión de la historia y la construcción de las identidades sociales y culturales en futuros maestros. 2018. Tesis (Doctorado en Didáctica de las ciencias, las lenguas, las artes y las humanidades) Universidad de Barcelona, Barcelona, 2018.

BENJAMIN, Walter. Tesis sobre la filosofia de la història. València: Ateneu de Benimaclet, 2007.

BIESTA, Gert. Democracia, ciudadanía y educación: de la socialización a la subjetivación. Foro de Educación, Salamanca, v. 14, n. 20, p. 21-34, 2016. Disponible en: https://doi.org/10.14516/fde.2016.014.020.003. Acceso en: 1 dic. 2020.

BLÄSI, Christoph. Educational publishers and educational publishing. In: FUCHS, Eckhardt; BOCK, Annekatrin (eds.) The palgrave handbook of textbook studies. New York: Palgrave Macmillan US, 2018. p. 73-93. Disponible en: https://doi.org/10.1057/978-1-137-53142-1_5. Acceso en: 1 enero 2021.

BLOCH, Marc. Mémoire collective, tradition, et coutume: a propos d'un livre récent. París: La renaissance du livre, 1925.

BOURDIEU, Pierre. Sistemas de enseñanza y sistemas de pensamiento. In: GIMENO SACRISTÁN, José; PÉREZ GÓMEZ, Ángel (eds.). La enseñanza: su teoría y su práctica Madrid: Akal, 1983. p. 20-36.

CARRETERO, Mario; BORRELLI, Marcelo. Memorias recientes y pasadas en conflicto: ¿cómo enseñar historia reciente en la escuela? Revista Cultura y educación, [s.l.], v. 20, n. 2, p. 201-215, 2008.

CARRETERO, Mario; LÓPEZ-MANJÓN, Asunción; JACOTT, Liliana. La explicación causal de distintos hechos históricos. In: CONSTRUIR Y ENSEÑAR: las ciencias sociales y la historia. [Buenos Aires]: Aique, 2002. p. 83-95.

CATALUÑA. Decret 143/2007, de 26 de juny, pel qual s'estableix l'ordenació dels ensenyaments de l'educació secundaria obligatòria. Diari Oficial de la Generalitat de Catalunya, [Barcelona], 29 jun. 2007. Disponible en: https://dibaaps.diba.cat/vnis/temp/CIDO_dogc_2007_06_20070629_DOGC_2007 0629_062_138.pdf. Acceso en: 15 dic. 2020 
CATALUÑA. DECRET 187/2015, de 25 d'agost, d'ordenació dels ensenyaments de l'educació secundària obligatòria Diari Oficial de la Generalitat de Catalunya, [Barcelona], 28 ago. 2015. Disponible en: https://portaldogc.gencat.cat/utilsEADOP/PDF/6945/1441278.pdf. Acceso en: 15 dic. 2020.

CUESTA, Raimundo. Historia con memoria y didáctica crítica. Revista ConCiencia Social, Salamanca, n. 15, p. 15-30, 2011.

CUESTA, Raimundo. La historia como disciplina escolar: génesis y metamorfosis del conocimiento histórico en las aulas. In: FORCADELL, Carlos; PEIRÓ, Ignacio (eds.). Lecturas de la historia: nueve reflexiones sobre historia de la historiografía. Zaragoza: Institución "Fernando el Católico", 2002. p. 221-254.

D22. [Cuestionario recogido por] Equipo de investigación proyecto Edumemorias, Barcelona, junio de 2020.

D23. [Cuestionario recogido por] Equipo de investigación proyecto Edumemorias, Barcelona, junio de 2020.

D36. [Cuestionario recogido por] Equipo de investigación proyecto Edumemorias, Barcelona, junio de 2020.

D85. [Cuestionario recogido por] Equipo de investigación proyecto Edumemorias, Barcelona, octubre de 2020.

D94. [Cuestionario recogido por] Equipo de investigación proyecto Edumemorias, Barcelona, octubre de 2020.

D161. [Cuestionario recogido por] Equipo de investigación proyecto Edumemorias, Barcelona, octubre de 2020.

D173. [Cuestionario recogido por] Equipo de investigación proyecto Edumemorias, Barcelona, octubre de 2020.

D175. [Cuestionario recogido por] Equipo de investigación proyecto Edumemorias, Barcelona, octubre de 2020.

D182. [Cuestionario recogido por] Equipo de investigación proyecto Edumemorias, Barcelona, octubre de 2020.

D219. [Cuestionario recogido por] Equipo de investigación proyecto Edumemorias, Barcelona, diciembre de 2020.

D234. [Cuestionario recogido por] Equipo de investigación proyecto Edumemorias, Barcelona, diciembre de 2020. 
D248. [Cuestionario recogido por] Equipo de investigación proyecto Edumemorias, Barcelona, diciembre de 2020.

D252. [Cuestionario recogido por] Equipo de investigación proyecto Edumemorias, Barcelona, diciembre de 2020.

DELGADO-ALGARRA, Emilio José; ESTEPA-GIMÉNEZ, Jesús. Educación ciudadana y dimensiones de la memoria en la enseñanza de las ciencias sociales: investigación sobre las concepciones del profesorado de educación secundaria de Huelva y provincia. Revista Educación XX1, Madrid, v. 20, n. 2, p. 259-278, 2017. Disponible en: https://doi.org/10.5944/educxx1.19041. Acceso en: 1 enero 2021.

DÍEZ GUITÉRREZ, Enrique. La asignatura pendiente: la memoria histórica democrática en los libros de texto escolares. España: Plaza y Valdés, 2020.

FLORES, Marcello; SILINGARDI, Claudio. An Italian reflection on history and memory. In: GUIXÉ I COROMINES, Jordi (ed.), Past and power: public policies on memory: debates, from global to local. Barcelona: Universitat de Barcelona Edicions, 2016. p. 144-152.

FOSTER, Stuart. Dominant traditions in international textbook research and revision. Education Inquiry, [s.l.], v. 2, n. 1, p. 5-20, 2011.

FUCHS, Eckhardt; HENNE, Kathrin. History of textbook research. In: FUCHS, Eckhardt; BOCK, Annekatrin (eds.). The palgrave handbook of textbook studies. New York: Palgrave Macmillan, 2018. p. 25-56. Disponible en: https://doi.org/10.1057/978-1-137-53142-1_3. Acceso en: 1 enero 2021.

GARCÍA, Margarita; GATELL, Cristina. Nou polis 4: ciències socials, història: educació secundària. Barcelona: Vicens Vives, 2012.

GARCÍA, Margarita. GiH 4, geografia e història, educació secundària. Barcelona: Vicens Vives, 2016.

GARCÍA, Margarita. Marca 4: ciències socials, història: educació secundària, quart curs. Barcelona: Vicens Vives, 2003.

GARCÍA, Miriam; DIESTRO, Alfonso. Ciudadanía e interculturalidad: elementos claves en la construcción de la identidad europea. Revista Interacções, Lisboa, n. 23, p. 2-29, 2013. Disponible en: https://doi.org/10.25755/INT.2816. Acceso en: 1 enero 2021

GARCíA, Nylza Offir. Educación, memoria histórica y escuela: contribuciones para un estado del arte. Revista Colombiana de Educación, [s.l.], v. 1, n. 79, p. 135-170, 2020. Disponible en: https://doi.org/10.17227/rce.num79-8918. Acceso en: 1 nov. 2020. 
GÓMEZ, Cosme Jesús, RODRÍGUEZ, Raimundo; MIRETE, Ana Belén. Percepción de la enseñanza de la historia y concepciones epistemológicas: una investigación con futuros maestros. Revista Complutense de Educación, Madrid, v. 29, n. 1. p. 237-250, 2017. Disponible en: https://doi.org/10.5209/RCED.52233. Acceso en: 1 oct. 2020.

GÓMEZ, Cosme Jesús; LÓPEZ, Ramón; RODRÍGUEZ, Jairo. La investigación en didáctica de las ciencias sociales en revistas españolas de ciencias de la educación: un análisis bibliométrico (2007-2017). Revista Didáctica de las Ciencias Experimentales y Sociales, Valencia, v. 37, n. 67, p. 67-88, 2019. Disponible en: https://doi.org/10.7203/dces.37.14440. Acceso en: 1 enero 2021.

GONZÁLEZ, Gustavo; SANTISTEBAN, Antoni. El lugar de la Memoria: una investigación sobre la formación del profesorado de Ciencias Sociales. Revista Educação em foco, [s.l.], v. 19, n. 3, p. 35-60, 2015.

HALBWACHS, Maurice. Memoria colectiva y memoria histórica. Revista REIS, Madrid, v. 69, p. 209-219, 1995.

HERNÁNDEZ-GUTIÉRREZ, José Antonio. Memoria mediática: la nostalgia en la cultura pop. Revista Question, Buenos Aires, v. 1, n. 62, p. 1-13, 2019. Disponible en: https://doi.org/10.24215/16696581e152. Acceso en: 1 feb. 2021.

HUYSSEN, Andreas. Resistencia a la memoria: los usos y abusos del olvido público. CONGRESSO BRASILEIRO DE CIÊNCIAS DA COMUNICAÇÃO, 27, Porto Alegre, 2004. Anais [...]. Porto Alegre: [s.n.], 2004. p. 1-16. Disponible en: http://intercom.org.br/memoria/congresso2004/conferencia_andreas_huyssen.p df. Acceso en: 1 enero 2021.

ILLIA, Laura; SONPAR, Karan; BAUER, Martin. Applying Co-occurrence Text Analysis with ALCESTE to Studies of Impression Management. British Journal of Management, [s.l.], v. 25, n. 2, p. 352-372, 2014. Disponible en:

https://doi.org/10.1111/j.1467-8551.2012.00842.x. Acceso en: 1 dic. 2020.

JELIN, Elisabeth. Memoria y democracia. Una relación incierta. Revista Política, Santiago de Chile, v. 51, n. 2, p. 129-144, 2013.

JELIN, Elizabeth. Historia, memoria social y testimonio o la legitimidad de la palabra. Revista IBEROAMERICANA, Berlín, v. 1, n. 1, p. 87-98, 2001. Disponible en: https://doi.org/10.18441/IBAM.1.2001.1.87-98. Acceso en: 1 oct. 2020.

JIMÉNEZ, Absalón; INFANTE, Raúl; AMANDA, Ruth. Escuela, memoria y conflicto en Colombia. Un ejercicio del estado del arte de la temática. Revista Colombiana de Educación, [s.l.], v. 62, p. 287-314, 2012.

LEVÍN, Florencia. Escrituras de lo cercano. Apuntes para una teoría de la historia reciente argentina. Revista Nuevo mundo mundos nuevos, [s.l.], 2017. Disponible en: https://doi.org/10.4000/nuevomundo.70734. Acceso en: 1 dic. 2020. 
LÓPEZ FACAL, Ramón; VALLS MONTÉS, Rafael. La necesidad cívica de saber historia y geografía. In: ALBA FERNÁNDEZ, Nicolás de; GARCÍA PÉREZ, Francisco F.; SANTISTEBAN, Antoni (eds.). Educar para la participación ciudadana en la enseñanza de las ciencias sociales. Madrid: Asociación Universitaria de Profesorado de Didáctica de las Ciencias Sociales, Díada, Madrid, 2012. p. 185 192.

LÓPEZ-FACAL, Ramón. Los «conflictos sociales candentes» en el aula. Revista Íber. Didáctica de las Ciencias Sociales, Geografía e Historia, Barcelona, n. 69, p. 8-20, 2011.

MARTÍNEZ, Hernando; ROZAS, Antón; SECO, Eduardo. Ciencias sociales, 8. Madrid: SM, 1995.

MARTÍNEZ, Nicolás; VALLS, Rafael; PINEDA, Francisco. El uso del libro de texto de historia de España en bachillerato: diez años de estudio, 1993-2003, y dos reformas (LGE-LOGSE). Enseñanza de las Ciencias Experimentales y Sociales, Valencia, n. 23, p. 3-35, 2009.

MARTÍNEZ, Rosendo. Profesores entre la historia y la memoria: un estudio sobre la enseñanza de la transición dictadura-democracia en España. Revista Enseñanza de las Ciencias Sociales. Revista de Investigación, Barcelona, n. 13, p. 41-48, 2014.

NORA, Pierre. El historiador es un árbitro de las diferentes memorias. Letras Libres, [s.l.], 1 feb. 2018. Disponible en: https://www.letraslibres.com/espanamexico/revista/entrevista-pierre-nora-el-historiador-es-un-arbitro-lasdiferentes-memorias. Acceso en: 1 oct. 2020.

OLICK, Jeffrey. K; ROBBINS, Joyce. Social memory studies: from "collective memory" to the historical sociology of mnemonic practices. Annual Review of Sociology, [s.l.], v. 24, n. 1, p. 105-140, 1998. Disponible en:

https://doi.org/10.1146/annurev.soc.24.1.105. Acceso en: 1 enero 2021.

ORELLANA, Cristian; MUÑOZ, Carlos. Escuela y formación ciudadana: concepciones de ciudadanía, formación ciudadana y del rol de la escuela.

Revista Electrónica Interuniversitaria de Formación del Profesorado, Murcia, v. 22, n. 2, 2019. Disponible en: https://doi.org/10.6018/reifop.22.2.370561. Acceso en: 1 enero 2020.

PINGEL, Falk. Nazioni ed Europa nell'educazione scolastica: come vediamo noi stessi e gli «altri»? In: INSEGNARE L'EUROPA: concetti e rappresentazioni nei libri di testo europei. Torino: Fondazione Giovani Agnelli, 2003. p. XIII-LXXII.

PINOCHET, Sixtina; URRUTIA, Néstor. Entre la academia y el aula: la aparición de actores marginados en la Historia y su enseñanza. Revista de Historia y geografía, Santiago de Chile, n. 34, p. 135-156, 2016. 
PRATS, Joaquín; VALLS, Rafel; MIRALLES, Pedro (eds.). Iberoamérica en las aulas: qué estudia y qué sabe el alumnado de educación secundaria. Lleida: Milenio, 2015.

PRATS, Joaquín (dir.). Los jóvenes ante el reto europeo: conocimientos y expectativas del alumnado de educación secundaria. Barcelona: Fundación «La Caixa», 2001.

PRATS, Joaquín. Combates por la historia en la educación. Revista Enseñanza de las ciencias sociales. Revista de investigación, Barcelona, n.15, p. 145-153, 2016. Disponible en: https://doi.org/10.1344/ECCSS2016.15.13. Acceso en: 1 oct. 2020.

PRATS, Joaquín. Memoria histórica y enseñanza de la historia. En: Isidora SáezRosenkranz; Joaquín Prats Cuevas (eds.), Memoria histórica y enseñanza de la historia. Gijón: Trea, 2020. p. 11-28.

RICOEUR, Paul. Historia y memoria. La escritura de la historia y la representación del pasado. In: PÉROTIN-DUMON, Anne (ed.). Historizar el pasado vivo en América Latina. [S.l.: s.n.], 2007. Disponible en:

https://www.casadevelazquez.org/fileadmin/fichiers/investigacion/Ateliers/Histo ria_y_memoria.pdf. Acceso en: 1 oct. 2020.

RUBIO, Graciela. Educación y memoria. Desafíos y tensiones de una propuesta. Revista Nómadas. Revista crítica de Ciencias Sociales y Jurídicas, Madrid, n. 1, p. 1-13, 2007.

SACAVINO, Susana. Pedagogía de la memoria y educación para el "nunca más" para la construcción de la democracia. Revista Folios, [s.l.], n. 41, p. 69-85, 2015.

SAENZ DEL CASTILLO, Aritza. ¡La enseñanza de la Historia sin mujeres!: género, currículum escolar y libros de texto: una relación problemática. Revista

Didáctica de las Ciencias Experimentales y Sociales, Valencia, n. 29, p. 43-59, 2015.

SÁlZ, Jorge. Alfabetización histórica y competencias básicas en libros de texto de historia y en aprendizajes de estudiantes. Didáctica de las Ciencias

Experimentales y Sociales, Valencia, n. 27, p. 43-66. 2013.

SAMMLER, Steffen. History of the school textbook. In: FUCHS, Eckhardt; BOCK, Annekatrin (eds.). The palgrave handbook of textbook studies. Nueva York:

Palgrave Macmillan, 2018, p. 13-23. Disponible en: https://doi.org/10.1057/978-1137-53142-1_2. Acceso en: 1 enero 2021.

SANTACANA, Joan; ZARAGOZA, Gonzalo (eds.). Historia: ciencias sociales: ciclo 2 (Secundaria). Madrid: SM, 1997.

SANTANDER, Pedro. Por qué y cómo hacer análisis de discurso. Cinta de 
Moebio, Santiago de Chile, n. 41, p. 201-224, 2011.

SANTISTEBAN, Antoni. Cómo trabajar en clase la competencia social y ciudadana. Aula de Innovación Educativa, Barcelona, n. 187, p. 12-15, 2009.

SECRETARÍA GENERAL TÉCNICA. El sector del libro en España. [Madrid]: Ministerio de Educación, Cultura y Deporte, Secretaría General de Educación y Formación Profesional, Centro de Investigación y Documentación Educativa: Morata, 2018.

SIERP, Aline. History, memory, and trans-European identity: unifying divisions. New York: Routledge, 2014.

SILVEIRA, Caroline. Fear and memory politics in Brazil. In: COROMINES, Jordi Guixé i (ed.). Past and power: public policies on memory: debates, from global to local. Barcelona: Universitat de Barcelona Edicions, 2016. p. 152-163.

SOLA, Salomé. Memoria mediática y construcción de identidades. Tabula Rasa, Bogotá, n. 19, p. 301-314, 2013. Disponible en:

https://revistas.unicolmayor.edu.co/index.php/tabularasa/article/view/1328. Acceso en: 1 dic. 2020.

TRAVESO, Enzo. El pasado, instrucciones de uso: historia, memoria, política. Madrid: Marcial Pons, 2007.

WILLIAMS, Raymond. Marxismo y literatura. Barcelona: Península, 2000.

WILLIAMS, Raymond. Sociología de la cultura. Barcelona: Paidós, 1981.

Universidade do Estado de Santa Catarina - UDESC

Programa de Pós-Graduação em História - PPGH

Revista Tempo e Argumento

Volume 13 - Número 33 - Ano 2021

tempoeargumento@gmail.com 